ISSN 1823-626X

Malaysian Journal of Fundamental and Applied Sciences

available online at http://mjfas.ibnusina.utm.my

\title{
Microstructure Studies of Strontium Titanate Thin Films Prepared by Sol-gel Dip Coating Method
}

Saleha Maarof*, Karim Deraman, W. Nurulhuda W. Shamsuri, Bakar Ismail and S.Aisah Mat

Department of Physics, Faculty of Science, UTM, 81310 UTM Skudai, Johor, Malaysia

Received 5 December 2012, Revised 25 March 2013, Accepted 18 April 2013, Available online 3 May 2013

\begin{abstract}
Strontium titanate $\left(\mathrm{SrTiO}_{3}\right)$ thin films were deposited on corning glass by using dip coating method. Strontium nitrate, titanium (IV) isopropoxite, ethylene glycol and nitric acid have been use to prepared sol-gel of strontium titanate. Structural and its surface morphologies of the films were characterize by using X-ray Diffraction (XRD) and Atomic Force Microscopy (AFM), respectively. It have been determine that the films were strontium nitrate compound for as-prepared sample with lattice parameter; $\mathrm{a}=\mathrm{b}=\mathrm{c}=0.78 \mathrm{~nm}$ and strontium titanate compound for annealing at 500 ${ }^{\circ} \mathrm{C}$ temperature with lattice parameter $0.39 \mathrm{~nm}$. The films annealed at $500{ }^{\circ} \mathrm{C}$ showed the films were polycrystalline with orientation; (110), (111), (200) and (211). The grain sizes were in the range of 17.4 to $60.7 \mathrm{~nm}$ and surface roughness in range 22.9 to $70.1 \mathrm{~nm}$.
\end{abstract}

| Thin Films $\mid \mathrm{SrTiO}_{3}$ | Dip Coating |

(B) 2013 Ibnu Sina Institute. All rights reserved. http://dx.doi.org/10.11113/mjfas.v9n3.98

\section{INTRODUCTION}

Strontium titanate $\left(\mathrm{SrTiO}_{3}\right)$ have been well known as a paraelectric material with a cubic perovskite structure [1]. Theoretically, strontium titanate materials are known to have properties such as high dielectric constant, good thermal stability, second order phase transformation, stress induce phase transition photo-activity, etc [2]. These advantages makes strontium titanate as the best material and widely used for application in memory cell capasitors for non-volatile memories or dynamic random access application (DRAM), microelectronic, solar and sensor technology. Usually in recent years, strontium titanate material is used in bulk or thin film technology development [3].

There are various methods of preparing nanostructure thin films such as sol-gel process (known as dip coating method [4,5] and spin coating method [6,7]), metal organic decomposition (MOD) [8], liquid phase deposition (LPD) [9], spray pyrolysis [10], thermal evaporation under vacuum [11] and etc. A lot of researchers are competing in producing thin films with a simple technique, large surface area, inexpensive, environmental friendly and non-pollution for industrial user. Dip coating with sol-gel process have been widely used to prepare thin films and ceramic powder. This type of method has an ability to control the stoichiometric literally at the molecular level. Previous report shown that thin films produce by sol-gel method were generally crack free and homogeneous [12].

In this present paper, we successfully synthesize strontium titanate thin films and optimize the limit setup by using dip coating with sol-gel process as well as to observe crystallization phase appeared on thin films.

This research may give better understanding towards crystallization of strontium titanate thin films with some limitation on the films preparation.

\section{EXPERIMENTAL}

\subsection{Synthesis of solution}

A precursor solution was prepared by using strontium nitrate and titanium (IV) isopropoxite as starting materials. The molar ratio between strontium and titanium are $1: 1$. Titanium ion was formed by slowly added titanium (IV) isopropoxite, nitric acid and ethylene glycol with molar ratio 1:4:16. Ethylene glycol was added to promote polymerisation between titanium ion and strontium nitrate. Strontium nitrate salt was dissolved by stoichiometric rules of anhydrous insolubility with deionized water. After homogenization, both of the solutions were mixed together to form strontium titanate polymeric solution. Polyesterification process was successfully synthesized after 24 hours of constant stirring in temperature around $60^{\circ}$ to $70{ }^{\circ} \mathrm{C}$. The sol-gel solution is in a high stability solution (pale yellow solution) with no appearance of precipitate even after couple of months. Figure 1 shows a flow chart for preparation of strontium titanate polymeric precursor solution. Table 1 shows list of raw materials and sources used for preparing strontium titanate precursor solution. 


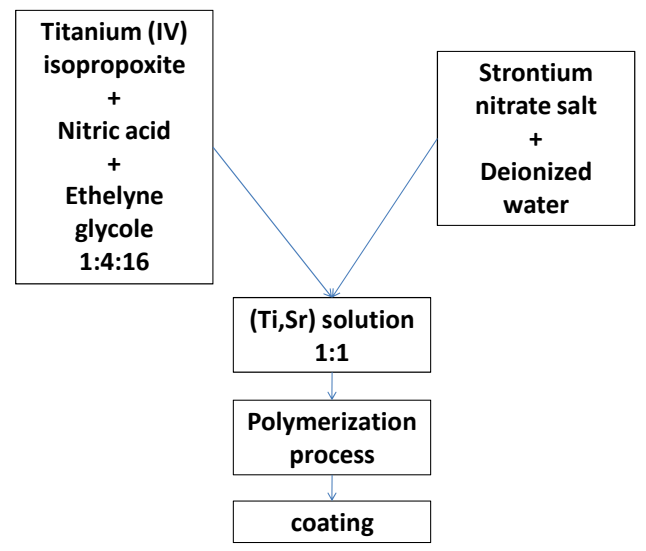

Fig. 1 Flow chart for preparation strontium titanate polymeric precursor method

Table 1 Raw materials used in preparing strontium titanate precursor solution

\begin{tabular}{|l|c|c|}
\hline \multicolumn{1}{|c|}{ Materials } & Source & Purity (\%) \\
\hline $\begin{array}{l}\text { Titanium (IV) Isopropoxite } \\
\left(\mathrm{C}_{12} \mathrm{H}_{28} \mathrm{O}_{4} \mathrm{Ti}\right)\end{array}$ & Acros Organics & 98.0 \\
\hline $\begin{array}{l}\text { Strontium Nitrate } \\
\left(\mathrm{Sr}\left(\mathrm{NO}_{3}\right)_{2}\right)\end{array}$ & QRëC & 99.5 \\
\hline $\begin{array}{l}\text { Ethylene } \mathrm{Glycol} \\
\left(\mathrm{HOCH}_{2} \mathrm{CH}_{2} \mathrm{OH}\right)\end{array}$ & Merck KGaA & 99.5 \\
\hline Nitric $\mathrm{Acid}\left(\mathrm{HNO}_{3}\right)$ & QRëC & 65.0 \\
\hline
\end{tabular}

\subsection{Sample preparation}

Corning substrate has been used as a medium to deposited thin films. The substrate was cleaned by using alcohol solution (acetone and ethanol) and distilled water for several times. The corning size is about $1 \mathrm{~cm}$ length $\times 2$ cm width.

Sample preparation was conducted in five steps: (1) Submerging a substrate vertically in the sol-gel by using a dip-coater machine (MTI Cooperation). (2) Withdrawing the substrate according to viscous force, surface tension and gravity of the sol by adjusting dip-coater speed setting. (3) A uniformly thin films will be formed after eliminating excess solution from substrate by drying vertically in a controlled temperature, $180{ }^{\circ} \mathrm{C}$ for 20 minutes. (4) Step 1 to 3 was repeated for producing multiple layers coated sample. One to five layers coated samples were used in this study. (5) All the samples were slowly heat-treated up to $300{ }^{\circ} \mathrm{C}$ for 2 hours (pyrolysis process). Then, all of the sample will be annealed at certain temperatures (crystallization process) by using a tube furnace.
Variable numbers of coating layer were prepared, from one layer to five layer coating sample. Temperatures for crystallization process were chosen from similar previous research as an indicator to form strontium titanate film crystal [2]. Table 2 shows the outline of film parameters.

Table 2 Preparative parameters for $\mathrm{SrTiO}_{3}$

\begin{tabular}{|c|c|c|}
\hline No & Parameters & Specification \\
\hline 1 & Rate of deposition & $5 \mathrm{~mm} / \mathrm{min}$ \\
\hline 2 & Layer coated & 1 - 5 layers \\
\hline 3 & Drying vertically & $180^{\circ} \mathrm{C}$ for 20 minutes \\
\hline 4 & Heat-treated (pyrolysis) & $300{ }^{\circ} \mathrm{C}$ for 2 hours \\
\hline 5 & Annealed (crystallization) & $\begin{array}{l}300^{\circ} \mathrm{C} \text { and } 500{ }^{\circ} \mathrm{C} \text { for } 2 \\
\text { hours }\end{array}$ \\
\hline 6 & Heating and cooling rate & $1^{\circ} \mathrm{C} \min ^{-1}$ \\
\hline
\end{tabular}

\subsection{Characterization}

Phase evaluation and structural information of the thin films were characterized by X-ray diffraction (XRD). The diffraction patterns were recorded by Bruker D8 Advance $\mathrm{X}$-ray machine with $\mathrm{Cu} \mathrm{K} \alpha$ radiation $(\lambda=0.15418$ $\mathrm{nm})$ for the purpose of measuring the Bragg's diffraction angle $2 \theta$ in the range $20^{\circ}$ to $60^{\circ}$ configuration. The scan speed was $1^{\circ} \mathrm{min}^{-1}$ with scan step of $0.025^{\circ}$.

The particles sizes as well as the surface morphology images for an accurate analysis of the sample surface were characterize by using Seiko Instruments Inc., Atomic Force Microscope (AFM). Scans were taken at room temperature with a frequency of $2 \mathrm{kHz}$. AFM with its tapping mode was used to obtain a 3- Dimensional image which may reconstruct the sample surface.

\section{RESULTS \& DISCUSSION}

\subsection{Phase evaluation}

Figure 2 (a-b) shows the X-ray diffraction patterns of thin films prepared for (a) as-prepared sample $\left(180{ }^{\circ} \mathrm{C}\right.$ for 20 minutes) and (b) annealed sample $\left(300{ }^{\circ} \mathrm{C}\right.$ for 2 hours, crystallization step). Figure 2(a) is known as an asprepared sample after going through eliminating excess solution process. While Figure 2(b) is a sample which was undergoing crystallization process with annealing temperature $300{ }^{\circ} \mathrm{C}$ for 2 hours. Both of these graphs shown the initial process for X-ray diffraction pattern of polymeric precursor method-grown strontium titanate thin films deposited on corning substrate before the films change from raw compound (strontium nitrate crystallization phase) into strontium titanate crystallization phase. 
From X-ray diffraction patterns in Figure 2(a), major peaks occurs at $22.8^{\circ}, 25.6^{\circ}, 32.5^{\circ}, 38.4^{\circ}, 40.2^{\circ}$, $46.7^{\circ}, 51.1^{\circ}$ and $52.5^{\circ}$ corresponding to interplanar spacing, $d_{h k l}=3.9 \mathrm{~mm}, 3.5 \mathrm{~nm}, 2.8 \mathrm{~nm}, 2.3 \mathrm{~mm}, 2.2 \mathrm{~mm}, 1.9 \mathrm{~nm}$, $1.8 \mathrm{~nm}$ and $1.7 \mathrm{~nm}$, respectively. Graph in Figure 2(a) shows strontium nitrate with low crystallization compounds and lattice parameters, $\mathrm{a}=\mathrm{b}=\mathrm{c}=0.78 \mathrm{~nm}$. On the other hand, Figure 2(b), a diffuse pattern is observed for film heat-treated at $300{ }^{\circ} \mathrm{C}$ indicating that the film is in amorphous phase. The major peaks for as-prepared sample can be seen clearly from the graph. After being heated again at $300{ }^{\circ} \mathrm{C}$, all the peaks were eliminated as shown in Figure 2(b). These results are similar as previous report by S.M. Zanetti et al. [13], the XRD observed in amorphous phase for films heat-treated at $300{ }^{\circ} \mathrm{C}$. This indicates that the films consist of an inorganic amorphous precursor.

Figure 3 (a-e) shows thin films with crystallize phase of strontium titanate perovskite cubic structure after being heated up to $500^{\circ} \mathrm{C}$ (crystallization). From Figure 3, four clear peaks can be detected for each layer at $32.4^{\circ}, 40.0^{\circ}$, $46.5^{\circ}$ and $57.8^{\circ}$. These peaks correspond to strontium titanate peaks at (110), (111), (200) and (211), respectively. The dominant peak for this research is at (110). All of these peaks and dominant peak are similar with previous report done by S.M. Zanetti et al. [13]. Lattice parameters calculated from $d$ value of the peak in the spectrum are; $a=$ $\mathrm{b}=\mathrm{c}=0.3903 \mathrm{~nm}$ as close as spectrum in bulk material; $\mathrm{a}=$ $\mathrm{b}=\mathrm{c}=0.3905 \mathrm{~nm}$. This value is in agreement as the ASTM values (data card 5-634). For crystallized strontium titanate thin films, only diffraction peaks assigned to strontium titanate crystallization were observed. This indicate no phase separation have occurred during annealing of the films from 300 to $500{ }^{\circ} \mathrm{C}$.

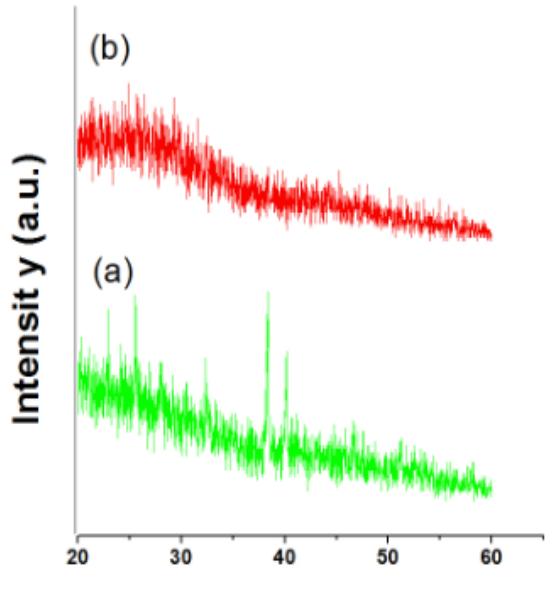

2- Theta-Scale

Fig. 2 XRD patterns films: (a) as prepared sample and (b) annealed sample at $300{ }^{\circ} \mathrm{C}$

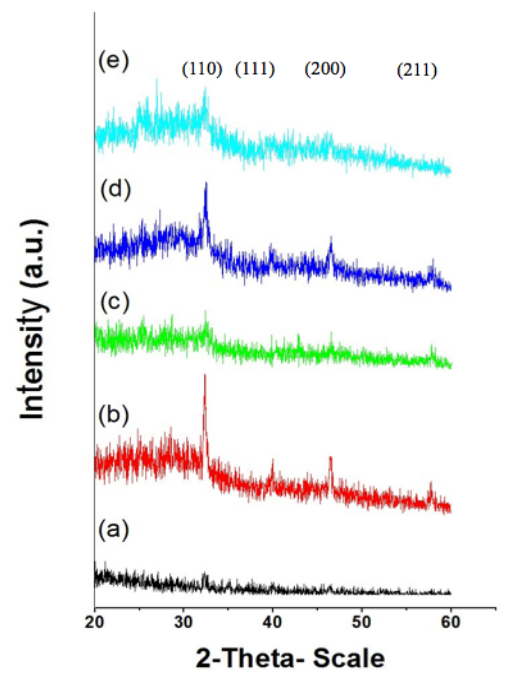

Fig. 3 XRD patterns of films synthesized at $500{ }^{\circ} \mathrm{C}$ heattreated: (a) one layer (b) two layers (c) three layers (d) four layers and (e) five layers.

In Figure 3, we are comparing thin films heat treated at $500^{\circ} \mathrm{C}$ in difference dipping layer from one layer coating sample to five layers coating sample. Increasing dipping layer will influence the X-ray diffraction detection in crystallization phase evaluation. Each layer will show the same dominant peak with difference intensity which is at angle $32.4^{\circ}$, (110). From our research, thin films dipping with two layers shows clearer peaks compared to other amount of dipping layers with its highest intensity compared to other sample.

The comparisons results between Figure 2 and Figure 3 were similar with previous report [14]. It says that amorphous phase was detected at temperature range between $300{ }^{\circ} \mathrm{C}$ and temperatures below than $500{ }^{\circ} \mathrm{C}$. More over, the process of strontium titanate crystallization is depends on the layer coating sample and heat-treatment. As the coating layer increase, the temperature should also be increased. This might be because of the strontium titanate reaction on the substrate need higher temperature to overcome the increasing of strontium titanate concentration when increasing the increase of coating layer. At temperature $500{ }^{\circ} \mathrm{C}$ and above, polycrystalline perovskite phase of strontium titanate compound were appeared [2]. What might be happen in as-prepared sample and sample heated between $300{ }^{\circ} \mathrm{C}$ to below $500{ }^{\circ} \mathrm{C}$ is a reaction process of the structure compound inside the films. This type of information was report in previous research. Leite et al. said, the amorphous films characterize by X-ray diffraction consists of an inorganic amorphous phase [6]. On the other hand, Ponte et al. said, no intermediate phase was observed which suggests a direct crystallization phase from the amorphous phase [7]. 


\subsection{Surface morphology and microstructure}

Figure 4 (a-c) shows the AFM photomicrograph 3Dimensional of strontium titanate thin films for sample heat-treated at $500{ }^{\circ} \mathrm{C}$ for 2 hours: (a) one layer dipping (b) two layers dipping (c) five layers dipping.

(a)

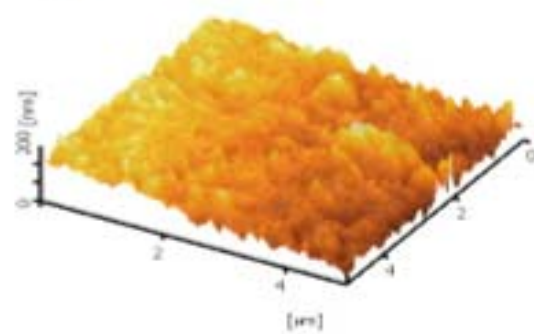

(b)

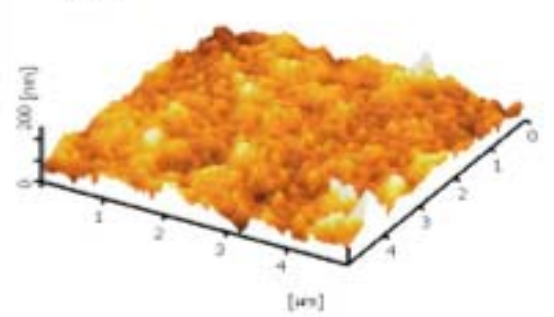

(c)

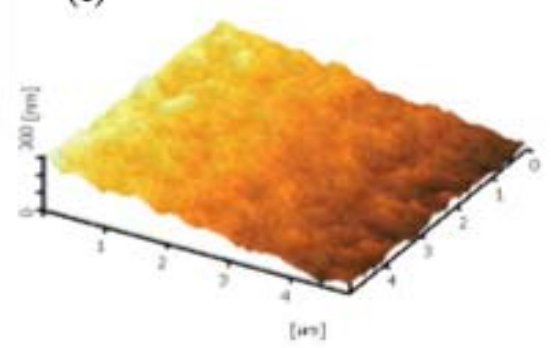

Fig. 4 AFM 3D images of thin films annealed at $500{ }^{\circ} \mathrm{C}$ for; (a) one layer (b) two layers and (c) five layers.

AFM analysis provides some information on the surface of the thin films such as average grain size and surface roughness $\left(R_{\mathrm{rms}}\right)$. These films were characterized as a smooth surface with a uniform, crack free microstructure and a densely packed. The average grain sizes are around 40.5, 17.4 and $60.7 \mathrm{~nm}$, respectively with mono, double and fifth-layered sample. On the other hand the average surface roughness, $\left(R_{\mathrm{rms}}\right)$ value are around $48.0,22.9,70.1 \mathrm{~nm}$, respectively with mono, double and fifth-layered sample. These results were calculated over an area of $5 \mu \mathrm{m}^{2}$. The fifth-layered film presented higher grain size and surface roughness.

From our report, the value of the grain size and surface roughness are not directly proportional with the number of dipping layer. This might be because of technical error and environment factor while preparing the sample.

\section{CONCLUSION}

We have shown that strontium titanate thin films were successfully prepared by sol-gel process. The films were deposited on a corning substrate using a dip-coater technique. The films were prepared in different numbers of dipping layer and annealing temperatures. The result produce by this method shows that this material is a perovskite cubic crystalline when being heated up to 500 ${ }^{\circ} \mathrm{C}$. As-prepared sample shows strontium nitrate with low crystallization compound. No intermediate phase was observed between temperatures higher than $300{ }^{\circ} \mathrm{C}$ and below than $500{ }^{\circ} \mathrm{C}$.

The X-ray diffraction result shows four clear peaks at (110), (111), (200) and (211) which approved similar to the theoretical result of strontium titanate material. The dominant peak is at (110). The AFM results shown that these films are smooth surface with a uniform, crack-free and a densely packed microstructure. The average grain size and surface roughness are around $17.4-60.7 \mathrm{~nm}$ and 22.9 $70.1 \mathrm{~nm}$, respectively. Through all the alignment analysis, we have revealed that the optimize parameters to produce a clear crystalline peaks with smooth surface and crack free is $500{ }^{\circ} \mathrm{C}$ heat-treated sample with two layer coating.

\section{ACKNOWLEDGEMENT}

The authors thank the Department of Physics, Faculty of Science, Universiti Teknologi Malaysia, Johor, the financial support from ministry of higher education (MOHE) under the vote 4F005 for funding the project.

\section{REFERENCES}

[1] S.M. Zanetti, E. Longo, J.A. Varela, and E.R. Leite, Mater. Lett., 31 (1997) 173-178.

[2] K.H. Kim, J.K. Park, C.H. Kim, H.D. Park, H. Chang, and S.Y. Choi, Ceram. Intern., 28 (2001) 29-36.

[3] B. Goran, B. Zorica, J.A. Varela, and E. Longo, J. Eur. Ceram. Soc., 24 (2004) 989-991.

[4] C. Xu, J. Huang, X. Tan, T. Yu, Z. Cui and L. Zhao, J. Dispersion Sci. Technol., 31 (2010) 1732-1739.

[5] F. M. Pontes, E.R. Leite, E.J.H. Lee, E.R. Leite, E. Longo, and J.A. Varela, J. Mater. Sci., 21 (2001) 419-426.

[6] M. N. Kamalasanan, N. Deepak Kumar, and Subhas Candra, J. Mater. Sci., 31 (1996) 2741-2745.

[7] Y. X. Zhou, S. Bhuiyan, S. Scruggs, H. Fang, M. Mironova, and K. Salama, Supercon. Sci. Technol., 16 (2003) 901-906.

[8] Y. Gao, Y. Masuda, T. Yonezawa, and K. Koumoto, Mat. Sci. Eng., B99 (2003) 290-293. 
[9] K.J.Kim, M. Suzuki, A. Yoshikawa, T. Fukuda, K.H. Auh, and K.C. Shin, J. Alloys Compounds, 440 (2007) 216-219.

[10] C. Dantus, R.S. Rusu, and G.I. Rusu, Superlattice and Microstructures, 50 (2011) 303-310.

[11] R. Edson, Leite, V.R. Mastelaro, S.M. Zenetti, and E. Longo, Mater. Res., 2 (1999) 93-97.
[12] F.M. Pontes, E.R. Leite, E.J.H. Lee, E. Longo, and J.A. Varela, J. Eur. Ceram. Soc., 21 (2000) 419-426.

[13] S.M. Zanetti, E.R. Leite, E. Longo, and J.A. Varela, J. Eur Ceram. Soc., 98 (1999) 1409-1412.

[14] S.M. Zanetti, E.R. Leite, E. Longo, and J.A. Varela, Appl. Organometallic Chem., 13 (1999) 373-382. 